\title{
Relação entre Tecnologias Digitais e Docência: a Compreensão de Licenciandos sobre Tecnodocência
}

\author{
Relationship between Digital Technology and \\ Teaching: the Undergraduates Understanding about \\ Technoteaching
}

LUCIANA DE LIMA

Universidade Federal do Ceará

ROBSON CARLOS LOUREIRO

Universidade Federal do Ceará

\begin{abstract}
Resumo: O objetivo é analisar de que forma licenciandos relacionam as tecnologias digitais com a docência. Considerando-se a fragmentação dos saberes e a subutilização das tecnologias digitais como problemas centrais na formação de professores, a pesquisa quantitativa com elementos de Survey apresenta por unidade de análise cento e quatro licenciandos participantes de formação e de disciplina em Tecnodocência entre 2013 e 2015 ofertadas pela Universidade Federal do Ceará. Realiza-se o planejamento da pesquisa com a elaboração do questionário on-line, aplicado com os licenciandos em seis semestres letivos subsequentes. Os dados são analisados a partir de elementos da Análise Textual Discursiva e da Estatística. Os equipamentos digitais mais citados foram tablets e lousa digital; os recursos digitais, vídeos e aplicativos para serem utilizados principalmente em pesquisas na internet e na transmissão do conteúdo centrada na ação do professor. Acreditam que as tecnologias digitais são pouco utilizadas na escola.
\end{abstract}

Palavras-chave: Tecnologias Digitais. Docência. Licenciatura. Tecnodocência.

\begin{abstract}
The goal is to analyze how undergraduates related digital technologies to teaching. Given the fragmentation of knowledge and the underuse of digital technologies as key issues in teacher formation, the quantitative research with Survey elements presents by analysis unit one hundred and four undergraduates participants of formation and discipline in Technoteaching between 2013 and 2015 offered by the Universidade Federal do Ceará. It carried out the research planning with the development of the online questionnaire administered to undergraduates in six subsequent semesters. The data are analyzed from elements of Discursive Textual Analysis and Statistics. The most cited digital equipment were tablets and digital whiteboard; the digital resources, videos and applications to be used mainly in research on the internet and in the transmission of content focused on the teacher's action. They believe that digital technologies are rarely used in school.
\end{abstract}

Keywords: Digital Technologies. Teaching. Degree Course. Technoteaching. 


\section{Introdução}

A Formação de Professores desde o século XX é estudada por pesquisadores em âmbito mundial e obtém constatações semelhantes. Em geral utiliza teorias de ensino não integradas à atualidade. Para Carr e Kemmis (1988, p. 125): "[...], as teorias são o produto de alguma atividade prática, [...] toda a atividade prática recebe orientação de alguma teoria". No caso da Formação de Licenciandos, são três os fatores que atestam falhas significativas: [1] a teoria trabalhada com os licenciandos se desconecta da prática; [2] as formações não enfatizam a importância da fundamentação epistemológica das ações didáticas e metodológicas; e [3] o uso das tecnologias digitais não produz novas metodologias e didáticas. De acordo com Tardif (2002), esse fato decorre de uma formação pouco eficiente que ainda se baseia em uma proposta aplicacionista do conhecimento.

Gatti (2010) ressalta a existência de uma pulverização dos conhecimentos, gerando uma fragilidade da preparação dos professores para o exercício da docência na Educação Básica. As ementas dos cursos demonstram falta de integração entre as disciplinas de formação específica e as de formação pedagógica. Os conteúdos são desarticulados; existe um desequilíbrio entre disciplinas teóricas e práticas, e, estão desvinculados das reflexões e possíveis integrações com as tecnologias digitais.

A simples incorporação dos conhecimentos vinculados às tecnologias digitais nos cursos de formação não garante uma transformação pedagógica e integradora de fato, apenas reforça uma prática vigente (COLL, 2009). Loureiro, Lima e Soares (2014), em pesquisa desenvolvida com professores de ensino superior, constatam que existe interesse dos docentes em se aprofundar no conhecimento sobre as novidades tecnológicas. No entanto, buscam empregálas em metodologias para a prática da docência, geralmente de forma expositiva. Mesmo diante de ferramentas que possibilitam a abertura para mudanças metodológicas, as práticas continuam semelhantes às comumente utilizadas. As mudanças se revelam mínimas, possivelmente por falta de formações que pensem propostas metodológicas diferenciadas integrando as Tecnologias Digitais da Informação e Comunicação (TDICs).

Considera-se que as tecnologias digitais estão presentes no cotidiano das pessoas e promovem inovações constantes do ponto de vista tecnológico digital, incorporadas rapidamente pelo universo social. Sejam novos equipamentos, sejam novos softwares utilizados on-line ou off-line, as TDICs promovem um incremento nas possibilidades de uso das tecnologias digitais no campo educacional, passíveis de adaptações. Considera-se ainda que, potencialmente, esses artefatos tecnológicos geram possibilidades de mudança no campo didático-metodológico e nas inter-relações entre professor e aluno por meio da compreensão de ensino, aprendizagem e avaliação descentralizada da ação do professor e em parceria com o aluno, de tal forma que ambos possam usufruir dos benefícios advindos de todos os processos cognitivos vivenciados.

No entanto, a produção de tecnologias digitais educacionais tem valorizado mais a ferramenta em si do que as ações didático-metodológicas do professor ao fazer uso dessas ferramentas no contexto da docência. O Banco Internacional de Objetos Educacionais (BIOE, 
2016) disponibiliza atualmente aproximadamente 20.000 objetos digitais para uso do professor em diferentes níveis, áreas e modalidades de ensino. O Portal do Professor (MEC, 2016) apesar de ser uma iniciativa para auxiliar o docente com sugestões de planos de aula, mídias de apoio, notícias sobre educação, iniciativas governamenais, interação com outros professores e possibilidades de curso de formação continuada é um recurso pouco utilizado nas formações de licenciandos na Universidade Federal do Ceará (UFC).

Apesar de serem iniciativas que apresentam o intuito de contribuir para a disseminação de ferramentas digitais para os professores em quaisquer níveis de formação, não se evidenciaram registros de que estes espaços contribuem para uma mudança da postura do professor em sala de aula frente ao uso das ferramentas digitais que se atualizam e se desenvolvem rapidamente. Diante dessa perspectiva, pergunta-se: como os licenciandos da UFC compreendem a utilização das TDICs na docência diante desse quadro de grande produção tecnológica digital e pouca modificação na prática docente que permanece pré-digital?

A UFC apresenta uma proposta de inserção das tecnologias digitais nos cursos de Licenciatura por meio de disciplinas obrigatórias e/ou optativas ofertadas semestralmente. Em 2013, montou o Laboratório Interdisciplinar de Formação de Educadores (LIFE/UFC), com o subsídio da CAPES, para atender também a formação de licenciandos para a integração entre tecnologias digitais e docência.

Dessa iniciativa nasceu a Formação de Licenciandos integrada à Cibercultura e Educação (LICIE) e a disciplina Tecnodocência ofertada para todas as Licenciaturas com coordenação direta da Pró-Reitoria de Graduação sob a supervisão da Coordenadoria de Formação e Aprendizagem Cooperativa (COFAC). Ofertadas semestralmente, com carga horária de 64 horas/aula, possibilita o estudo integrativo entre TDICs e docência por meio da interdisciplinaridade, da aprendizagem significativa e de estudos arqueo-genealógicos sobre a epistemologia da docência. Pesquisas têm sido realizadas desde 2013 e discutidas no Grupo de Pesquisa Tecnodocência em fase de oficialização em 2016.

Considerando-se esse contexto, o objetivo da investigação é analisar de que forma os licenciandos relacionam as tecnologias digitais com a docência ao iniciarem suas atividades pedagógicas na Formação LICIE e na disciplina Tecnodocência ofertadas entre os anos de 2013 e 2015 na UFC.

\section{Relação entre Tecnologias Digitais e Docência na contemporaneidade}

O formato do artigo deve ser em folha A4, 2,1 cm para margem superior, 2,6 cm para margem inferior e 2,8 cm para margens laterais, com cabeçalhos e rodapés apresentados neste modelo. A fonte principal deve ser Verdana, tamanho nominal de 9 pontos, com espaço de 1,5 entre as linhas. $\mathrm{O}$ arquivo do artigo em formato doc ou docx. Todos os parágrafos devem ter um recuo de $0,5 \mathrm{~cm}$.

Os trabalhos devem respeitar ao limite de 33.000 a 50.000 caráteres com espaço. Outro tipo de papel é a revisão do livro de experiência ou relatório de experiência. Estes devem 
ser 1.500 a 3000 palavras e o mesmo formato que o papel. Resumo da tese deve ser de 150 a 500 palavras.

Os artigos deverão ter sua extensão ditada pela necessidade de clareza na explicitação dos argumentos, respeitado o limite de 33.000 a 50.000 caracteres com espaço, incluindo resumo e abstract, títulos, notas de fim e referências bibliográficas.

Os títulos e subtítulos destacados em negrito, fonte 11, e numerados sequencialmente;

As citações breves no interior do parágrafo, entre aspas. As citações longas (com mais de três linhas) devem ser recuadas $4 \mathrm{~cm}$, em letra tipo Verdana tamanho 8 , espaço simples $(1,0)$. Já os títulos e fontes das figuras (jpg; png), quadros, tabelas, bem como notas de fim (quando houver devem ser colocadas antes das referências) devem ser numerados e terem fonte de tamanho 7.

$\mathrm{Na}$ contemporaneidade, docentes e discentes estão imersos em uma onda tecnológica que tende a se homogeneizar na sociedade. Para Mitcham e Mackey (2004), a perspectiva idealista que se expressa nos países produtores e exportadores de tecnologias, tende a valorizar a prática e os resultados, ao mesmo tempo que supõe certa liberdade de transformação e inclusão das tecnologias e da técnica em suas tradições e estereótipos consolidados na sociedade.

Contudo, em relação à ação docente, a integração das TDICs parece se construir numa perspectiva de separação entre a técnica e seu uso amplo pelos cidadãos. Sua integração na sala de aula e na profissão da docência pode se relacionar à possibilidade de uso integrado das TDICs como forma potencial para mudanças didáticas e metodológicas da ação prática do professor a partir das necessidades de estudo de técnicas vinculadas aos conhecimentos dos equipamentos, dos recursos tecnológicos, bem como dos conteúdos específicos de cada área do saber e dos conhecimentos prévios dos alunos.

Nesse sentido, Lima e Loureiro (2014) salientam que o uso das tecnologias digitais no cotidiano pessoal e profissional é corriqueiro para docentes e discentes. Aguiar (2014) ao pesquisar como licenciandos de cursos semipresenciais se relacionam com as TDICs, identifica que $98,51 \%$ dos sujeitos pesquisados acredita em seu uso no âmbito da docência. Esse aspecto pode evidenciar probabilidades maiores da incorporação das tecnologias digitais nesse contexto educacional. No entanto, de acordo com pesquisas desenvolvidas por Gatti (2010), devido à quase inexistência de discussões sobre tecnologia digital nos cursos de Licenciatura, e com uma formação fragmentada, os licenciandos e professores quase não utilizam esses recursos no âmbito escolar.

Apesar de se utilizar com bastante frequência as tecnologias digitais na sociedade contemporânea, ainda que se possa considerar como uma ação ou incorporação em relação à vida cotidiana dos cidadãos que têm acesso aos artefatos e serviços tecnológicos, a forma de utilização não é ingênua, mas carregada de significados políticos, morais e sociológicos (MITCHAM; MACKEY, 2004). Esse aspecto pode fornecer indícios sobre as dinâmicas sociais, sobretudo para a formação dos docentes, que não denotam uma reflexão além de aplicabilidades possíveis. Segundo Gomez (2004), o uso da rede de computadores e a considerada cibercultura criaram relações sociais que impactam nos âmbitos econômico e 
político, gerando novos espaços de poder vinculados ao conhecimento com abertura para ações educativas.

Quando se une a força do computador como ferramenta ao alto poder de transmissão promovido pelo acesso à internet, torna-se possível a criação de interfaces que expõem informações que podem ser geradas, armazenadas, resgatadas, processadas e transmitidas, utilizando como base uma linguagem digital comum (CASTELLS, 1999).

Em razão destas reflexões espera-se mais da adesão das TDICs em processos de ensino, aprendizagem e avaliação. Echeverría (2001, p.280) detalha:

[...] no sólo se trata de transmitir información y conocimientos gracias a las TIC, sino que, además, hay que capacitar a las personas para que puedan actuar competentemente en los diversos escenarios electrónicos y con los distintos instrumentos (o interfaces) que permiten acceder al tercer entorno. Para ello hay que diseñar, construir y mantener nuevos escenarios e instrumentos educativos con los que las personas puedan aprender a moverse e intervenir en el espacio electrónico.

Como se evidencia, existe uma manutenção de estado ignorante do docente sobre as possibilidades de integração das TDICs à sua prática profissional. Reconhece-se o uso pessoal das tecnologias pelo cidadão, mas não se percebe a importação destas para o trabalho docente.

Existe ainda o aspecto da banalização do uso das ferramentas que os jovens tendem a escolher, caracterizando-as como inadequadas para o uso na educação. Recuero (2011) afirma que as interações podem se espalhar por diversas plataformas digitais, porém percebe-se que existem características que fazem algumas plataformas serem mais bem aceitas que outras. Por isso observa-se que, as mídias menos conhecidas, mesmo que se configurem como redes sociais, possuem baixos níveis de conhecimentos relatados, pois não foram aderidas facilmente às rotinas dos atores sociais.

Na contemporaneidade, a tecnologia está integrada na sociedade e no exercício profissional. Ellul (2004) assevera que a técnica está imbricada no entorno social alterando significativamente as relações entre as pessoas. É de se esperar que estas alterações também influenciem as conexões entre os docentes e a prática docente alterando o "faber" na sala de aula.

Considera-se que a escolha da tecnologia é pautada por uma formação cultural, uma vez que as tecnologias digitais passam a fazer parte da cultura contemporânea, penetrando também no âmbito da educação, embora nem sempre vivenciada em sua plenitude (ALMEIDA; SILVA, 2011). Esta construção cultural segundo Foucault (2000), denota um tipo de poder social que atua sobre a vida, sobre as populações e que denominou de biopoder. Esse poder se traduz na ação das instituições sobre os indivíduos, sobre os corpos de uma forma maximizada, deixando de atuar sobre um sujeito ou sobre um corpo e passando a influenciar as populações e os grupos sociais. Logo, o biopoder constrói a cultura.

Se, para filósofos da tecnologia como Ellul (2004) que sugere estar a técnica imbricada ao entorno social e vinculada a transformações no domínio humano, e para Mumford (2004) explicitando que a tecnologia possibilita outras formas de comunicação interferindo no alcance e na velocidade de contato entre os sujeitos, torna-se evidente a necessidade dos docentes que 
desejam atuar na contemporaneidade de se apropriarem das questões técnicas, já que essa rejeição Ihes defasa do contexto atual. Essa situação de rejeição não seria um problema se estes profissionais (docentes) compreendessem sua situação de formadores na sociedade contemporânea.

De outro lado, Levy (2000) e Echeverría (2001) percebem a necessidade de capacitação constante do docente para uso de artefatos tecnológicos e da necessidade de se atuar dentro de paradigmas pedagógicos docentes atualizados e contextualizados. Estas reflexões sobre a necessidade de aproximação do docente com a tecnologia digital demonstram como novas técnicas docentes se potencializam ao serem vinculadas aos artefatos tecnológicos sem os quais, na atualidade, não poderia ser praticada.

\section{Metodologia}

A pesquisa de caráter quantitativo, com elementos de Survey (BABBIE, 2003), foi desenvolvida com cento e quatro (104) estudantes da Universidade Federal do Ceará (UFC), participantes da Formação LICIE (Formação de Licenciandos integradas à Cibercultura e Educação) nos semestres de 2013.1, 2013.2, 2014.1 e 2014.2, e da disciplina Tecnodocência nos semestres de 2015.1 e 2015.2 subsidiada pela CAPES com apoio da Pró-Reitoria de Graduação.

A unidade de análise da pesquisa é composta por uma amostra não probabilística por conveniência, uma vez que cada estudante participante da coleta de dados o fez espontaneamente de acordo com a presença na data da coleta. Sendo assim, a unidade de análise representa $85 \%$ da população que compõe a Formação LICIE e a disciplina Tecnodocência nesse período.

A faixa etária média dos estudantes é de vinte e sete (27) anos. São advindos de treze (13) cursos de Licenciatura, contemplando quase a totalidade dos cursos ofertados pela UFC para a formação de professores da educação básica: Letras (26,0\%), Química $(15,4 \%)$, Matemática $(9,6 \%)$, Ciências Biológicas $(8,7 \%)$, Geografia $(8,7 \%)$, Ciências Sociais $(7,7 \%)$, Filosofia $(6,7 \%)$, Física $(5,8 \%)$, Pedagogia (5,8\%), Educação Física (2,9\%), História $(1,0 \%)$, Matemática $(1,0 \%)$, Teatro $(1,0 \%)$. Apenas os estudantes do curso de Licenciatura em Dança não procuraram participar das formações. Cursam principalmente os últimos semestres letivos: a partir do 70 semestre $(59,6 \%)$, entre o 40 e $\circ 6^{\circ}$ semestres $(20,2 \%)$, entre $\circ 1^{\circ}$ e $\circ 3^{\circ}$ semestres $(20,2 \%)$. Considerando-se a faixa etária média e o fato de cursarem os semestres finais com mais frequência, pode-se inferir que os estudantes participantes da pesquisa apresentam características de estudantes veteranos na UFC.

A maior parte dos estudantes não recebe bolsa da UFC (59,6\%). Daqueles que recebem bolsa, 57,1\% estão vinculados a projetos com atividades de docência, tais como o Programa Institucional de Bolsa de Iniciação à Docência (PIBID), o Programa de Iniciação à Docência (PID) e Estágio de Docência. A maior parte dos estudantes já atua na docência (54,9\%) com experiência no Ensino Fundamental I (7,5\%), Ensino Fundamental II $(32,8 \%)$, Ensino Médio $(44,8 \%)$, dentre outros $(14,9 \%)$, como Curso de Idiomas, Aulas de Reforço Escolar, por 
exemplo. É possível inferir que os estudantes apresentam experiência com a docência dentro e/ou fora da Universidade.

Todos eles utilizam computador e internet. Quanto ao local de uso, 77,9\% dos estudantes prefere utilizar em casa, $17,3 \%$ prefere utilizar na Universidade, os demais, utilizam no trabalho, na casa de amigos ou em lan houses. Quanto à frequência de uso, 86,5\% dos estudantes utilizam todos os dias, $9,6 \%$ faz uso três vezes por semana e os demais fazem uso apenas uma vez por semana. Navegam principalmente pelas redes sociais $(32,1 \%)$, em busca de informações para realização de trabalhos acadêmicos $(29,4 \%)$, em busca de informações sobre profissão e trabalho $(20,8 \%)$, para entretenimento $(13,7 \%)$ e para outras atividades $(4,1 \%)$.

A UFC proporciona disciplinas obrigatórias, optativas e livres, ofertadas semestralmente, com reflexões sobre o uso das tecnologias digitais na docência a todos os cursos de Licenciatura. Para aqueles vinculados às Ciências da Natureza, existe apenas uma disciplina obrigatória. Para os demais cursos são disciplinas optativas ou livres. Geralmente são ministradas em salas de aula convencionais, sem equipamentos digitais, com conteúdos abordados apenas teoricamente, sem interlocução com a prática docente. Com a inserção da Formação LICIE em 2013, devido à montagem do Laboratório Interdisciplinar de Formação de Educadores (LIFE/UFC) com subsídios da CAPES, iniciou-se um processo de discussão a respeito da ampliação das discussões teórico-práticas sobre a integração entre TDICs e docência na UFC.

A partir de 2015, a disciplina Tecnodocência foi criada como optativa para todos os cursos de Licenciatura, hospedada na Pró-Reitoria de Graduação sob a coordenação da Coordenadoria de Formação e Aprendizagem Cooperativa (COFAC). Apresenta como objetivo integrar os conteúdos teóricos às atividades práticas da docência com o desenvolvimento de planejamentos e materiais educacionais integrados às TDICs. Trata-se, portanto, de uma iniciativa para que os licenciandos tenham a oportunidade de iniciar estudos e reflexões sobre o uso das tecnologias digitais em sala de aula. Ofertada semestralmente, com 64 horas/aula, os encontros presenciais, acontecem no LIFE/UFC. Os encontros virtuais acontecem via grupo fechado no Facebook. Estão disponíveis recursos digitais como ultrabooks, tablets, lousa digital, internet, câmeras fotográficas e filmadoras digitais bem como recursos não digitais: mesa, cadeira, armário, lousa, pincel, apagador, papel, entre outros.

A disciplina Tecnodocência desenvolve uma proposta metodológica interdisciplinar integrada às TDICs pautada no estudo teórico-prático da Teoria da Aprendizagem Significativa de Ausubel (AUSUBEL; NOVAK; HANESIAN, 1980), da Teoria de Fluxo de Czikszentmihalyi (1990), da Filosofia da Diferença com enfoque em Foucault (2000), dos conceitos de Interdisciplinaridade ressaltados por Japiassu (1976) e da proposta Construcionista de Papert (2008). Possibilita a valorização e a utilização dos conhecimentos prévios dos participantes, a construção do engajamento e do significado dos conceitos envolvidos e o desenvolvimento do pensamento crítico-reflexivo sobre a prática docente.

A pesquisa está concebida em três (3) etapas: planejamento, coleta e análise de dados. $\mathrm{Na}$ etapa 1, é elaborado o instrumento de coleta de dados no formato digital e armazenado em 
nuvem para ser disponibilizado aos estudantes da Formação LICIE e da disciplina Tecnodocência de acordo com seus respectivos cronogramas, acordados com os respectivos professores. Na etapa 2, é aplicado o questionário com os estudantes no primeiro dia de aula da formação e da disciplina. É importante que os estudantes ainda não tenham participado de nenhuma discussão sobre as temáticas abordadas, atribuindo maior confiabilidade à origem das informações. A coleta é realizada em seis (6) momentos de acordo com os semestres letivos: 2013.1, 2013.2, 2014.1, 2014.2, 2015.1, 2015.2.

O questionário contempla trinta (30) questões dispostas em duas (2) partes. Na primeira parte, os alunos respondem sobre aspectos pessoais, profissionais e acadêmicos com o intuito de caracterizar seu perfil. Na segunda parte, os alunos respondem perguntas conceituais sobre os conteúdos abordados na formação e na disciplina. Para este trabalho contempla-se a análise de apenas uma (1) questão que denota a compreensão sobre a relação entre tecnologias digitais e docência: "Em sua opinião de que forma as TDICs estão presentes no processo de ensino, aprendizagem e avaliação dos conteúdos trabalhados na escola?".

A análise de dados se pauta em alguns elementos que compõem os procedimentos da Análise Textual Discursiva (MORAES; GALIAZZI, 2011) em conjunto com elementos básicos da Estatística (BABBIE, 2003). Diante de um processo organizado para a compreensão do fenômeno estudado e a busca dos elementos emergentes da pesquisa utiliza-se uma sequência composta por quatro (4) fases: unitarização, categorização, descrição e interpretação.

$\mathrm{Na}$ fase da unitarização os textos escritos pelos estudantes (corpus) são desmontados para a busca e a definição das unidades de análise. Posteriormente, são reescritas com atribuição de um título, representando sua ideia central. Na fase da categorização, agrupam-se elementos semelhantes, por meio da comparação das unidades de análise. Utiliza-se um método indutivo, construindo-se as categorias emergentes a partir das informações captadas do corpus. A partir das categorias são definidas as variáveis de análise. Na fase da descrição são calculadas as frequências absolutas e relativas para cada variável exemplificadas pelos textos comprobatórios produzidos pelos estudantes retirados do corpus. Na fase da interpretação desenvolve-se uma leitura teórica dos fatos empíricos, estabelecendo-se uma relação entre as descrições interpretativas e os aspectos teóricos que compõem a pesquisa bibliográfica em busca de inferências sobre o fenômeno estudado.

As variáveis definidas são caracterizadas como nominais representadas por porcentagens a partir da quantificação de suas frequências absolutas e relativas. Totalizam quatro (4) variáveis: equipamento digital, recurso digital, metodologia de ensino e contexto. A primeira variável diz respeito aos equipamentos digitais mencionados pelos estudantes ao responderem o questionário vinculando-os aos elementos da docência. A segunda, trata dos recursos digitais mencionados, subdividindo-se em recursos on-line, quando utilizados na internet e recursos off-line, quando utilizados no computador sem a necessidade de acesso à rede. A terceira, trata das diferentes formas que os estudantes pensam a utilização das tecnologias digitais na docência. A quarta, vincula-se ao contexto de uso da tecnologia digital no sentido de explicitar as possibilidades reais da escola e dos alunos para utilização de equipamentos e recursos digitais na ação docente. 


\section{Resultados e Discussão}

Figuras e legendas, quadros, tabelas, esquemas e outros devem ser centrados, numeradas (os) sequencialmente, como mostrado na Figura 1. A fonte da legenda deve ser Verdana, 7 pontos, com 12 pontos de espaço antes e depois de cada legenda. A fonte da (o) mesma (o) deve ser colocada embaixo, mesmo quando elaborada (o) pelos próprios autores.

Considerando-se a variável equipamento digital (gráfico 1), os licenciandos mencionam primeiramente os Tablets (30,0\%), seguido da Lousa Digital (25,0\%) e do Projetor $(20,0 \%)$ como equipamentos digitais a serem utilizados na docência. Os Celulares $(10,0 \%)$ são lembrados com menor ênfase provavelmente pelo fato de a escola não autorizar sua utilização em sala de aula. Computador (5,0\%), por exemplo, é pouco mencionado. Outros equipamentos não digitais subdividem as preferências: a Lousa convencional (5,0\%) e a Televisão (5,0\%). É importante ressaltar que os licenciandos não mencionam o Notebook, por exemplo, como uma opção de ferramenta digital apesar de o projetor ser um artefato digital que se torna útil quando conectado a um computador ou notebook, a não ser que esteja equipado de forma integrada com algum processador de dados.

Percebe-se que a utilização de equipamentos digitais está equalizada com aquilo que é oferecido nas escolas, seja por programas governamentais ou por tradição, como é o caso do projetor. Contudo, um fenômeno que influencia o controle exercido pela governamentalidade é a menor presença dos celulares entre as respostas mais cotadas. Uma indicação de que as proibições e regras são reproduzidas pelos futuros docentes.

Gráfico 1 - Equipamentos Digitais mencionados pelos licenciandos

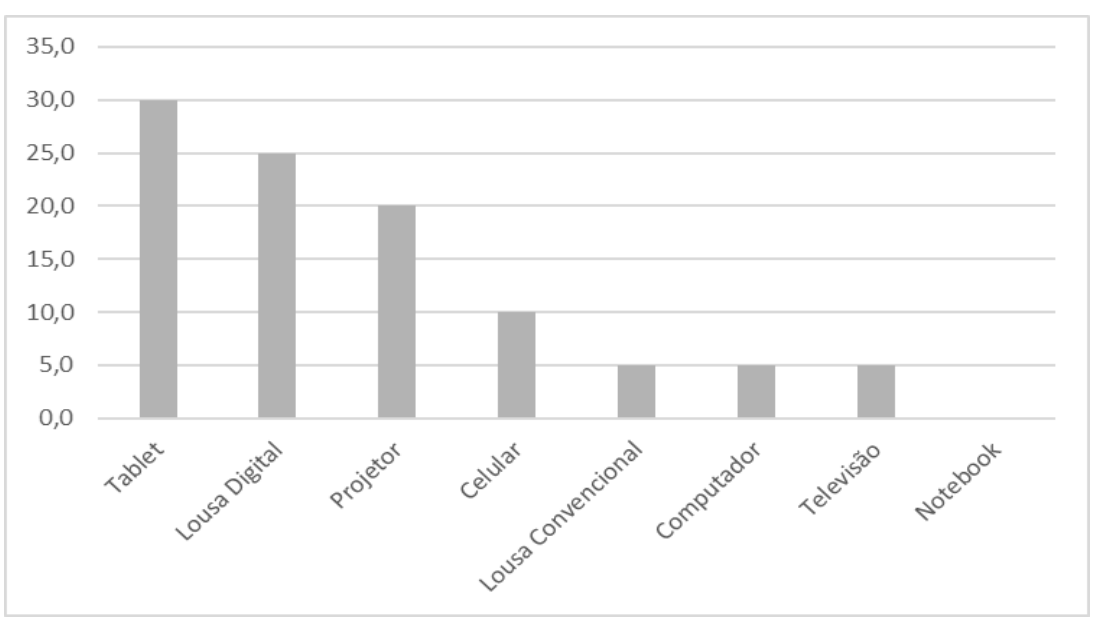

Fonte: própria, 2016.

Observa-se também que o uso da Lousa Digital implica em softwares bastante específicos para que seja utilizada de forma adequada, criando uma dependência de financiamentos governamentais ou de financiadores particulares, enfatizando o controle sobre os conteúdos e abordagens utilizados. O licenciando parece se conformar à oferta de conteúdo disponibilizado pela instituição. 
Em relação a Televisão, Baudrillard (2003) explica sobre o simulacro, uma experimentação, chegando às casas dos telespectadores, reações "vendidas" como sociais de um cotidiano aceito como normal, mas que na verdade em nada difere das experiências de estímulos promovidas por pesquisadores em ratos de laboratório, denotando a artificialidade de uma realidade inventada com uma finalidade bem designada em termos de controle e disciplinamento. Assim, a Televisão deixa de ser dispositivo institucional e passa a ser um dispositivo do cotidiano comum, ainda mantendo seu caráter de disciplinamento. Semelhante fenômeno ocorre com a Lousa convencional, equipamento não digital mas tão imbricado no ideário dos licenciandos ao ponto de serem citados conjuntamente aos equipamentos digitais.

A questão tratada também evidencia a declaração sobre os equipamentos que emergiram da pesquisa como isolados, como se pudessem funcionar por si, sem a dependência de outros, revelando um desconhecimento de seus esquemas técnicos necessários ao bom funcionamento das máquinas. Faz-se menção sobre tablets e lousa digital, mas não se encontra menção sobre conexão de internet e outros artefatos tecnológicos imprescindíveis para o uso destes. Essa falta de conexão se assemelha à fragmentação dos conhecimentos que os licenciandos vivenciam em seu processo formativo. Além disso, denota o conhecimento pautado no senso comum sobre as tecnologias digitais, evidenciando o que Gatti (2010) apresenta sobre as formações inicias de professores em que a discussão sobre as TDICs na docência é quase inexistente.

Considerando-se a variável recurso digital (gráfico 2), com ênfase nos recursos audiovisuais, os licenciandos optam primeiramente pelo vídeo $(53,1 \%)$, seguido das imagens $(21,9 \%)$ e do áudio (15,6\%), provavelmente menos pensado a ser utilizado em sala de aula como um recurso, uma vez que concorre com a própria fala do professor.

Gráfico 2 - Recursos Audiovisuais mencionados pelos licenciandos

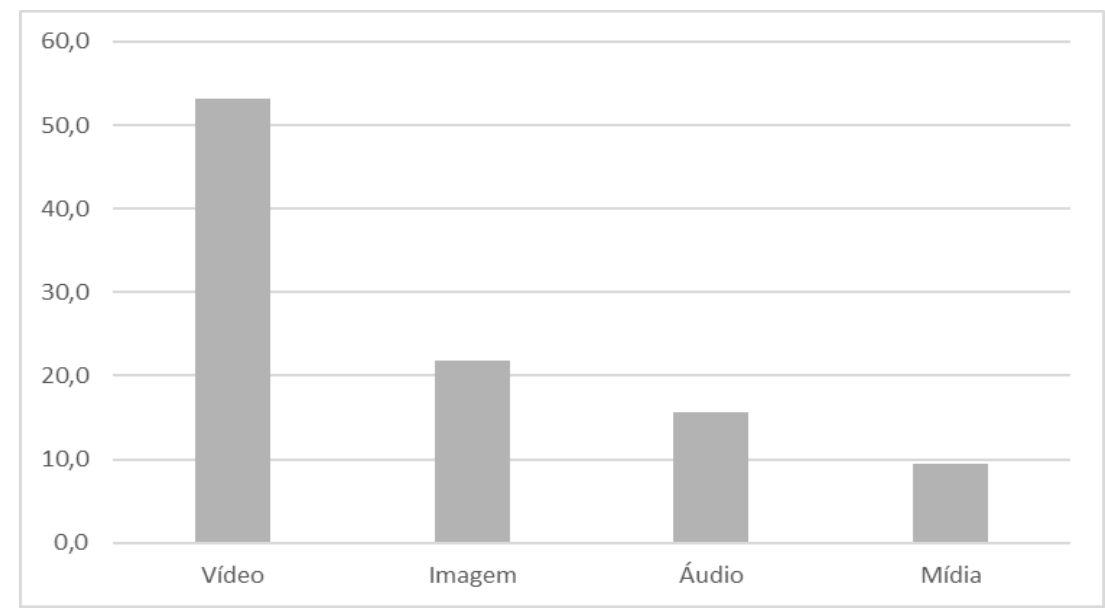

Fonte: própria, 2016. 
Recuero (2011) afirma que as interações podem se espalhar por diversas plataformas digitais, porém percebe-se que existem características que fazem algumas plataformas serem mais bem aceitas que outras. O tipo de linguagem tecnológica utilizada revela que existe uma vinculação do tipo de recurso com a popularidade deste na sociedade. O uso mais amplo do vídeo está provavelmente relacionado com a popularidade da televisão e do cinema.

O uso destas linguagens se realiza dentro da mesma lógica tradicional das aulas, onde o professor, nesse momento, relaciona a sua ação humana com o vídeo. Se numa aula inspirada na tradição a atenção dos alunos se convergem para o professor, com o uso destas linguagens a atenção será para o vídeo, para o áudio, para ambos. A relação esquematizada é a mesma: a atenção de muitos se converge obrigatoriamente para um ponto. Os alunos olham e ouvem o professor, olham e ouvem o vídeo, olham a imagem ou ainda, ouvem o vídeo. A atenção e raciocínio do grupo se converge para um único ponto da mesma forma que são trabalhadas as aulas expositivas, com pouca ou nenhuma interação do aluno com os conteúdos, as pessoas e/ou os recursos.

São poucos os licenciandos que citam explicitamente a internet como um recurso digital, apenas $8,7 \%$. No entanto, citam recursos que só podem ser utilizados a partir da internet. Essa percepção é interessante uma vez que o recurso digital pode estar intrinsecamente relacionado com o local onde ele se situa, de tal forma que a internet pode estar vinculada ao site e se pode pensar o site ao invés da internet como se fossem únicos.

Infere-se que os respondentes não vinculam algumas ferramentas e possibilidades com a necessidade de conexão de qualidade com a grande rede, levando à exposição de um desconhecimento técnico evidente. Para Echeverría (2001) é necessário capacitar as pessoas para o uso das TDICs de uma forma geral por meio do desenho, da construção e da manutenção de cenários e instrumentos educativos. Essa capacitação, no entanto, não se trata de um simples curso para conhecer os recursos e equipamentos, mas para contextualizarem esse conhecimento na docência com o intuito de se apropriarem do conhecimento a partir da integração entre teoria e prática, tornando significativo o processo de aprendizagem.

Dos recursos digitais citados pelos licenciandos (gráfico 3), o que apresentou maior destaque foram os aplicativos para tablet $(15,8 \%)$, provavelmente porque sejam os mais difundidos atualmente na internet com facilidade de acesso e de manipulação. As simulações, os jogos educativos e os slides foram citados igualmente como segunda opção ( $13,2 \%$ cada). Em geral, as simulações e os jogos estão disponíveis na internet com facilidade, enquanto que os slides são mais utilizados para produção do professor ou do aluno off-line.

A utilização de softwares educativos também foi uma opção de destaque entre os licenciandos (10,5\%). Percebe-se, no entanto, uma generalidade na compreensão do uso desse tipo de recurso digital, uma vez que não especificam qual software utilizariam em suas práticas pedagógicas, além de não reconhecer as simulações e os slides também como softwares. Os ebooks $(5,3 \%)$, as redes sociais $(5,3 \%)$ e os sites educativos $(5,3 \%)$ foram menos citados, embora sejam bastante difundidos socialmente. Os demais, modelagem, animação e tutorial ( $7,8 \%$ no total) são especificidades menos difundidas entre os licenciandos, apesar de serem conhecidas. 
Gráfico 3 - Recursos Digitais mencionados pelos licenciandos

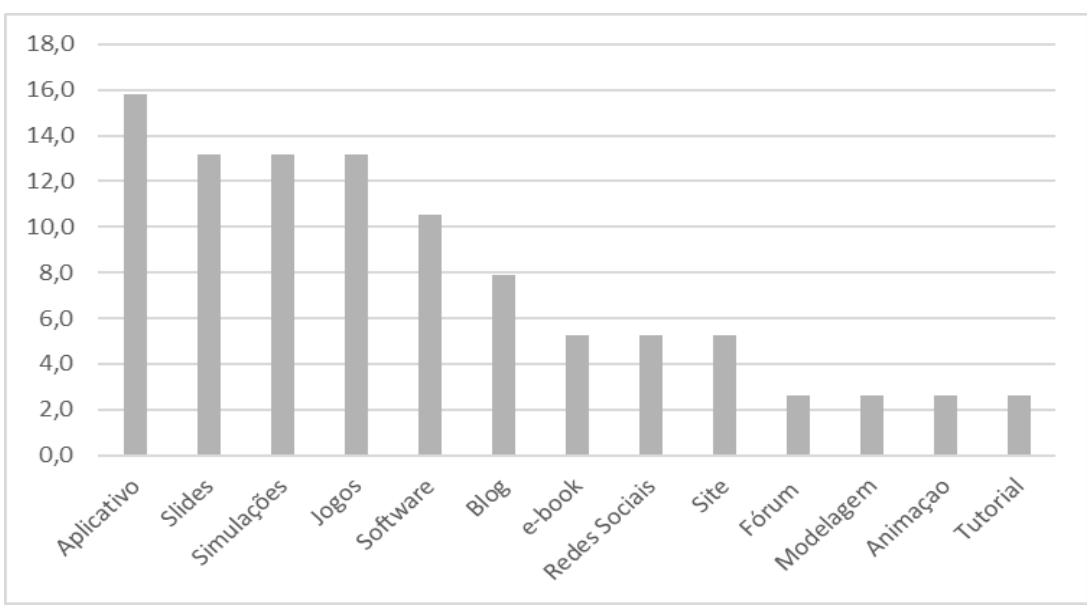

Fonte: própria, 2016.

Com relação à variável metodologia de ensino (gráfico 4), os licenciandos foram bastante genéricos no tipo de atividade que poderiam realizar com os alunos. 40,9\% afirmou que poderiam utilizar as TDICs para desenvolver atividades, sem qualquer especificação; outros $40,9 \%$ poderiam desenvolver atividades avaliativas. Os demais especificaram as dinâmicas em grupo $(9,1 \%)$, o trabalho com projetos $(4,5 \%)$ e as oficinas $(4,5 \%)$. Esse aspecto pode denotar o quanto o licenciando carece de compreender quais didáticas e metodologias podem ser aplicadas ou desenvolvidas com o uso das tecnologias digitais, demonstrando o quanto se torna compreensível quando o professor em sala de aula adapta o uso das tecnologias digitais às práticas comumente utilizadas.

Gráfico 4 - Metodologia de Ensino mencionada pelos licenciandos

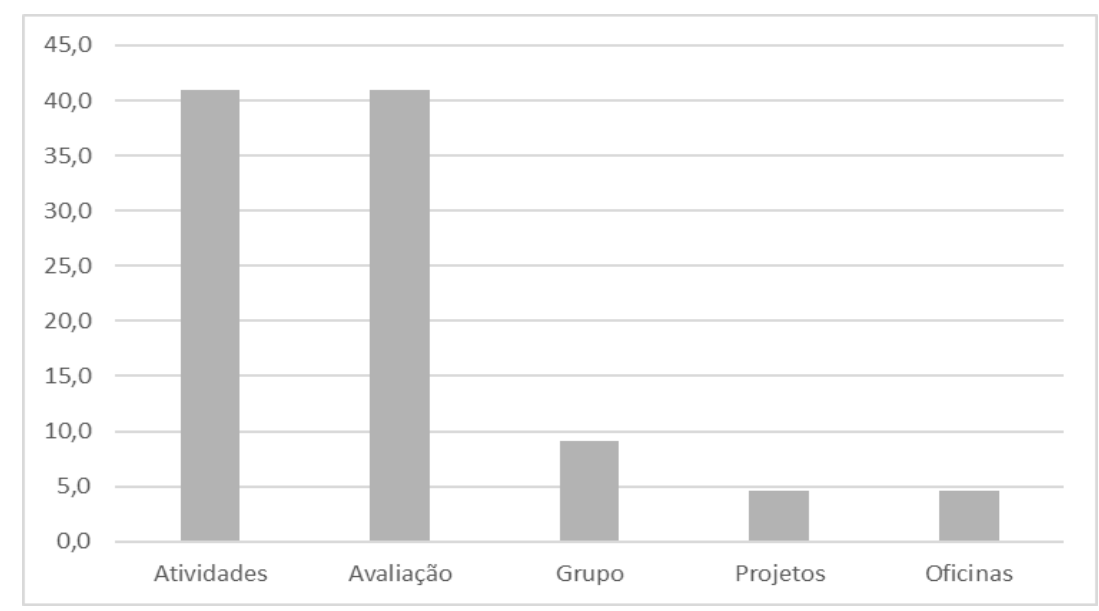

Fonte: própria, 2016.

Em relação às ações de ensino (gráfico 5 ), os licenciandos afirmam que as tecnologias digitais auxiliam os alunos nas pesquisas principalmente realizadas na internet $(18,3 \%)$; 
servem também para auxiliar na transmissão dos conhecimentos em aulas expositivas $(16,3 \%)$; facilitam a aprendizagem $(11,5 \%)$ e despertam o interesse do aluno $(11,5 \%)$ tornando as aulas mais prazerosas. Para outros, a interação entre aluno-aluno e professoraluno é facilitada por meio do uso das TDICs (10,6\%). Os elementos inovadores da utilização das tecnologias digitais em sala de aula, tais como dinamizar, construir, socializar e interdisciplinarizar, acontecem na compreensão de poucos licenciandos, mas existem no universo de pensamento somando $21,2 \%$ dos relatos coletados.

Esses aspectos revelam o quanto o licenciando ainda está conectado com a ideia do repasse de informações de forma expositiva e pensa o uso das TDICs para esse fim. Parecem se ater mais fortemente na superficialidade do processo a partir do interesse que a novidade possa despertar no aluno, sem citar o engajamento na aula e o significado da compreensão dos conteúdos como partes integrantes do processo de ensino, aprendizagem e avaliação. No entanto, alguns já trazem a necessidade de propostas que podem contribuir para a modificação do que está proposto como didáticas e metodologias que precisam ser modificadas para gerar transformações na forma de ensinar e aprender no contexto das TDICs.

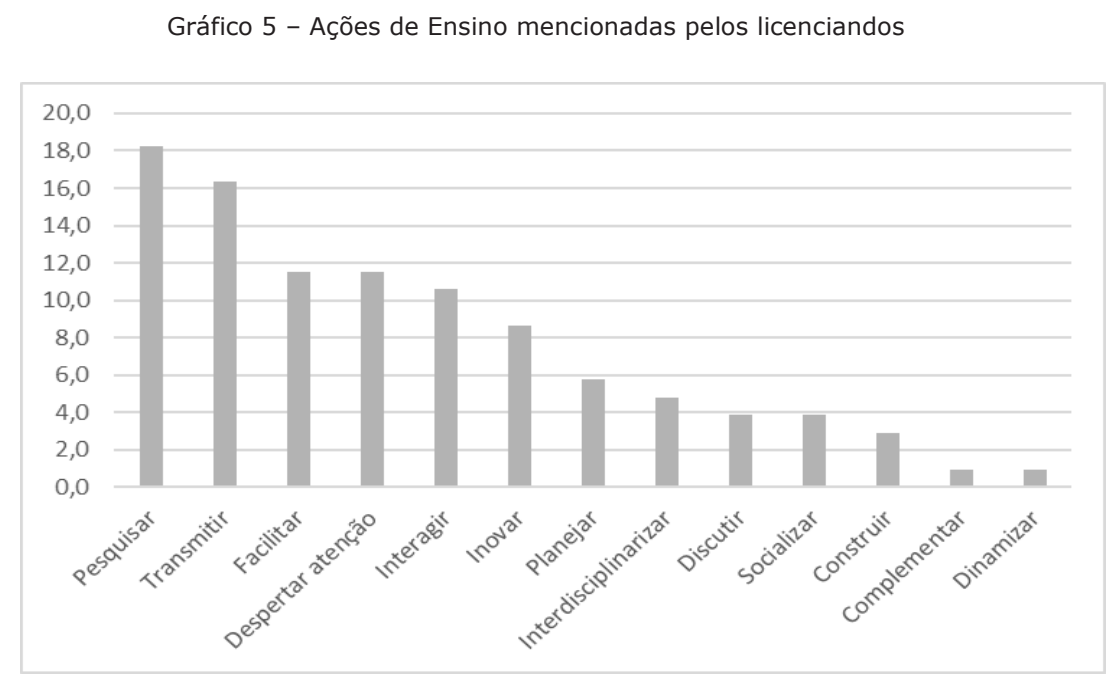

Fonte: própria, 2016.

Evidencia-se, dessa forma, o despreparo de conhecimento técnico sobre os recursos digitais que pretendem utilizar (GOMEZ, 2004; ECHEVERRÍA, 2001; RECUERO, 2011), mostrando, sobretudo, a dificuldade que apresentam em associá-los às didáticas e metodologias comumente utilizadas. Esse aspecto corrobora com a perspectiva de Coll (2009) ao afirmar que o professor utiliza as tecnologias digitais no âmbito da docência da mesma forma que o faz quando não a tem disponível. A prática pedagógica sem mantém, reproduz a prática vigente.

Com relação à variável contexto, menos de 1,0\% dos licenciandos acredita que os alunos já têm acesso às tecnologias digitais e esse aspecto é suficiente para que saibam como funcionam. Para $14,4 \%$ as tecnologias são pouco utilizadas na escola, quando o são. Esse aspecto revela que a escola ainda pode estar reticente na implementação das tecnologias 
digitais e na preparação de seus professores para essa integração. No total, 4,8\% dos licenciandos preferiu não opinar sobre a relação entre TDICs e docência.

\section{Considerações Finais}

A legenda da tabela deve ser colocada antes da tabela (ver Tabela 1) e a fonte usada também deve ser Verdana, 7 pontos, com 12 pontos de espaço antes e depois de cada legenda. As tabelas diferem dos quadros porque trazem dados numéricos e são abertas nas laterais, enquanto os quadros trazem informações textuais ou mistas e são fechados nas laterais. Devem trazer o título na parte superior e a fonte embaixo (mesmo quando elaborada pelos próprios autores).

Diante dos problemas de fragmentação dos saberes na formação docente e da subutilização das TDICs quando inseridas no contexto educacional, buscou-se analisar de que forma os licenciandos relacionam as tecnologias digitais com a docência ao iniciarem suas atividades pedagógicas na Formação LICIE e na disciplina Tecnodocência ofertadas entre os anos de 2013 e 2015 na UFC.

Percebeu-se que as escolhas dos equipamentos e recursos digitais estão pautadas nas propostas com maior apelo econômico e político da contemporaneidade evidenciando uma conformação dos licenciandos àquilo que a mídia e a governamentalidade impõem à sociedade e à escola. A desconexão que estabelecem entre os equipamentos pode evidenciar também indícios de uma fragmentação vivenciada em seu processo formativo, além de um distanciamento dos conhecimentos técnicos inerentes à tecnologia digital devido a uma formação cuja discussão sobre o tema é quase inexistente (GATTI, 2010).

A escolha pelos recursos audiovisuais, com maior ênfase nos vídeos e opção metodológica pela transmissão de conteúdos pode denotar uma tendência à utilização das tecnologias digitais centradas na ação do professor e uma superficialidade no uso dos recursos digitais, uma vez que a ênfase é atribuída à atração dos alunos para as aulas diante de um visual que desperta o interesse. Considerando-se as afirmações de Coll (2009), é possível que os licenciandos ainda não tenham despertado para outras ações pedagógicas mais voltadas para a preocupação com a aprendizagem dos alunos fazendo ou não uso das tecnologias digitais em sua prática docente.

Ainda assim, alguns licenciandos optaram por ações docentes inovadoras, ao pensarem a pesquisa na internet realizada também pelos alunos no sentido de promover a construção e a socialização do conhecimento a partir de ações interdisciplinares. Outros, porém, mostraram não acreditar que as tecnologias digitais podem ser utilizadas na docência, uma vez que as escolas estão pouco preparadas para esta finalidade.

Percebeu-se, portanto, que se faz necessário repensar o processo formativo dos licenciandos da UFC no sentido de acrescentar novas discussões teóricas e práticas sobre a integração entre tecnologias digitais e docência nos currículos das Licenciaturas, especialmente diante das reflexões atuais sobre a Base Nacional Comum Curricular (BNCC) que impacta na Educação Básica e na Formação de Professores, sobretudo, na Formação Inicial. Pretende-se continuar com a pesquisa em disciplinas e cursos de extensão da UFC no ano de 2016 que se preocupam com a utilização das tecnologias digitais na docência. 


\section{Referências}

AGUIAR, B C. A integração de Tecnologias Digitais de Informação e Comunicação pelos futuros professores: das relações entre tecnologias, formação, produção e apropriação dos licenciandos do programa LICIE_UAB_UFC sobre as TIC. Trabalho de Conclusão de Bacharelado. Sistemas e Mídias Digitais. Instituto Universidade Virtual. Universidade Federal do Ceará, 2014.

ALMEIDA, M. E. B. de; SILVA, M. da G. M. da. Currículo, tecnologia e cultura digital: espaços e tempos de web currículo. Revista e-curriculum, São Paulo, v.7, n.1, p. 1-19, abril, 2011.

AUSUBEL, D. P; NOVAK, J. D.; HANESIAN, H. Psicologia Educacional. Rio de Janeiro: Interamericana, 1980.

BABBIE, E. Métodos de Pesquisas de Survey. Belo Horizonte: Editora UFMG, 2003.

BANCO INTERNACIONAL DE OBJETOS EDUCACIONAIS. BIOE. Disponível em: <http://objetoseducacionais2.mec.gov.br/>. Acesso em: 15 jan. 2016.

BAUDRILLARD, J. A Sociedade de Consumo. Lisboa: Edições 70, 2003.

CARR, W.; KEMMIS, S. Teoria crítica de la enseñanza: la investigación-acción en la formación del profesorado. Barcelona: Ediciones Martinez Roca, 1988.

CASTELLS, M. A sociedade em rede - A era da informação: Economia, Sociedade e Cultura. São Paulo: Paz e Terra, 1999.

COLL, C. Aprender y enseñar con las TIC: expectativas, realidad y potencialidades. In CARNEIRO, R.; TOSCANO, J. C.; DÍAZ, T. Los desafíos de las TIC para el cambio educativo. Madrid, España: Fundación Santillana, 2009.

CZIKSZENTMIHALYI, M. Flow: the psychology of optimal experience. New York: Harper Perennial, 1990.

ECHEVERRÍA, J. Educación y sociedad de la información. Revista de Investigación Educativa, Barcelona, v. 19, n. 2, p. 277-289, 2001.

ELLUL, J. El orden tecnológico. In: MITCHAM, C.; MACKEY, R. (eds.). Filosofía y tecnología. Madrid: Encuentro, 2004, p. 112-151.

FOUCAULT, M. Em defesa da sociedade: Curso no Collège de France (1975-1976). São Paulo: Martins Fontes, 2000.

GATTI, Bernardete A. Formação de Professores no Brasil: características e problemas. Educ. Soc. Campinas, v. 31, n. 113, p. 1355-1379, out.-dez, 2010. Disponível em: <http://www.cedes.unicamp.br>. Acesso em: 02 abr. 2015.

GOMEZ, M.V. Educação em Rede: uma visão emancipadora. São Paulo: Cortez, Instituto Paulo Freire, 2004.

JAPIASSU, H. Interdisciplinaridade e patologia do saber. Rio de Janeiro: Imago, 1976.

LEVY, P. Cibercultura. São Paulo: Editora 34, 2000.

LIMA, L; LOUREIRO, R. O uso das Tecnologias Digitais da Informação e Comunicação (TDIC) na prática docente de Professores Universitários. In: Encontro Nacional de Didática e Práticas de Ensino, 17., 2014, Fortaleza. Anais do XVII Encontro Nacional de Didática e Práticas de Ensino. Fortaleza: UECE, 2014.

LOUREIRO, R.; LIMA, L. de; SOARES, A. Docência Universitária no Contexto das Tecnologias Digitais da Informação e Comunicação. Anais do XIX Congreso Internacional de Informática Educativa. Brasil, Fortaleza, 2014.

MINISTÉRIO DA EDUCAÇÃO. Portal do Professor. Disponível em: < http://portaldoprofessor.mec.gov.br/index.html>. Acesso em: 21 jan. 2016. 
MITCHAM, C.; MACKEY, R. Filosofía y tecnología. Encuentro: Madrid, 2004.

MORAES, R.; GALIAZZI, M. do C. Análise Textual Discursiva. Ijuí: Ed. Unijuí, 2011.

PAPERT, S. A Máquina das Crianças: repensando a escola na era da informática. Porto Alegre: Artmed, 2008.

MUMFORD, L. La Técnica y la naturaliza del hombre In: MITCHAM, C.; MACKEY, R. (eds.), Filosofía y tecnología. Madrid: Encuentro, 2004.

RECUERO, R. Redes Sociais na internet. Porto Alegre: Sulina, 2011.

TARDIF, M. Saberes docentes e formação profissional. Petrópolis, RJ: Vozes, 2002.

Submetido para avaliação em 05 de abril de 2016

Aprovado para publicação em 21 de junho de 2016

\section{Luciana de Lima}

Instituto Universidade Virtual - Universidade Federal do Ceará - UFC, Brasil, luciana@virtual.ufc.br

\section{Robson Carlos Loureiro}

Instituto Universidade Virtual - Universidade Federal do Ceará - UFC, Brasil, robson@virtual.ufc.br 